\title{
COVID-19 cases: definitive, or not?
}

Ethem Bilgiç

Department of General Surgery, Izmir Bozkaya Research and Education Hospital İzmir, Turkey

Corresponding Author: Ethem Bilgiç, Department of General Surgery, Izmir Bozkaya Research and Education Hospital İzmir, Turkey E. Mail: blakened_22@yahoo.com Received date: August 27, 2020: Accepted date: August 31, 2020: Published date: October 02, 2020

Citation: Ethem Bilgiç (2020) COVID-19 cases: definitive, or not? J. Clinical Medical Reviews and Reports 2(7); DOI: 10.31579/ 2690-8794/041 Copyright: () 2020, Ethem Bilgiç, This is an open access article distributed under the Creative Commons Attribution License, which permits unrestricted use, distribution, and reproduction in any medium, provided the original work is properly cited.

\begin{abstract}
Context: A cluster and increase in pneumonia cases with unknown cause were detected in Wuhan, Hubei province, China, in December 2019. These cases were reported to be associated with a new coronavirus type by the Chinese health authorities on January 7, 2020. The first case in Turkey was diagnosed on March 11, 2020. COVID-19 (SARS-CoV-2 infection) guide was prepared for the pandemic by the Ministry of Health scientific committee. However, despite strong clinical, laboratory and radiological suspicions, there are also patients who do not meet the exact case definition.
\end{abstract}

Case report: In this case report, we aimed to discuss two cases that did not meet the definitive case definition and followed up in our clinic.

Conclusions: Although gold standard method for the definitive diagnosis of SARS-CoV-2 infection is PCR, rapid antibody tests and CT findings are used in combination with PCR for a more effective struggle in the pandemic process would enhance rapid diagnosis of cases, necessary treatment and isolation measures to prevent transmission. It is thought that it would be useful to make case definitions.

Key words (MeSH terms): severe acute respiratory syndrome corona virus 2; corona virus Pandemics

Authors" key words: rapid antibody test; coronavirus disease 2019; antibody test kit

\section{Introduction}

Coronaviruses are common among humans, mammals and birds; enveloped ribonucleic acid (RNA) viruses that cause respiratory, enteric, hepatic and neurological diseases. There are six types of coronavirus known to cause disease in humans. Four of them (229E, OC43, NL63 and HKU1) typically cause cold symptoms in individuals with healthy immune systems. The other two are SARS-CoV which cause severe acute respiratory syndrome and MERS-CoV, which causes Middle East Respiratory Syndrome. They are zoonotic infections with mortality rates of $9.6 \%$ and $34.4 \%$, respectively $[1,2]$.

A cluster and increase in pneumonia cases with unknown cause were detected in Wuhan, Hubei province, China, in December 2019 [3, 4]. These cases were reported to be associated with a new coronavirus type by the Chinese health authorities on January 7, 2020. The World Health Organization (WHO) termed the clinical picture of the new coronavirus "corona virus disease 2019" (COVID-19) and the virus that caused this disease severe acute respiratory syndrome coronavirus 2 (SARS-CoV-2) on February 11, 2020 [5]. The main transmission routes of the virus have been reported as respiratory droplets and close contact between people. After that, COVID-19 has spread all over the world and has become a global public health problem.

The first case in Turkey was diagnosed on March 11, 2020. COVID-19 (SARS-CoV-2 infection) guide was prepared for the pandemic by the Ministry of Health scientific committee. This guideline contains information about the virus that caused COVID-19, ways of transmission, case definition, diagnostic methods, and strategy and behavior patterns for COVID-19 case or contacted in follow- up. The "COVID-19 (2019-nCoV Disease) Guide" is updated in line with current WHO recommendations and current scientific developments. According to this guide, cases with SARS-CoV-2 detected by molecular methods (polymerase chain reaction) from respiratory samples are defined as definitive cases [6]. However, despite strong clinical, laboratory and radiological suspicions, there are also patients who do not meet the exact case definition.

\section{Objective}

In this case report, we aimed to discuss two cases that did not meet the definitive case definition and followed up in our clinic.

\section{Case reports}

We declare that all patients gave their consent to have their cases to reported.

Case 1: Our first case, a 69-year-old male patient applied to our emergency department with complaints of fever and cough on 27.03.2020. It was learned from the anamnesis of the patient that he came from Istanbul to Didim by bus on 25.03.2020, traveled with his wife and his complaints had been present for five days. The patient had a history of hypertension and antihypertensive use. In the physical examination of the patient, fever was measured as $37.9 \mathrm{oC}$. System examination was normal. White blood cells (WBC): $4.32 \mathrm{~K} / \mu \mathrm{L}(4.6-10.2 \mathrm{~K} / \mu \mathrm{L})$, platelet count (PLT): $115 \mathrm{~K} / \mu \mathrm{L}(142-424 \mathrm{~K} / \mathrm{CRL})$, creactive protein (CRP): 8.4 $\mathrm{mg} / \mathrm{L}(0-5 \mathrm{mg} / \mathrm{L})$ was determined in laboratory tests. In the non-contrasted 
thorax computed tomography (CT) examination, "Peripherally located ground-glass views and patches of stone in the middle lower zones in both lungs are noteworthy. The peripheral location and patterns of the lesions were evaluated as highly significant in terms of COVID-19." as reported (Figures 1A and 1B).

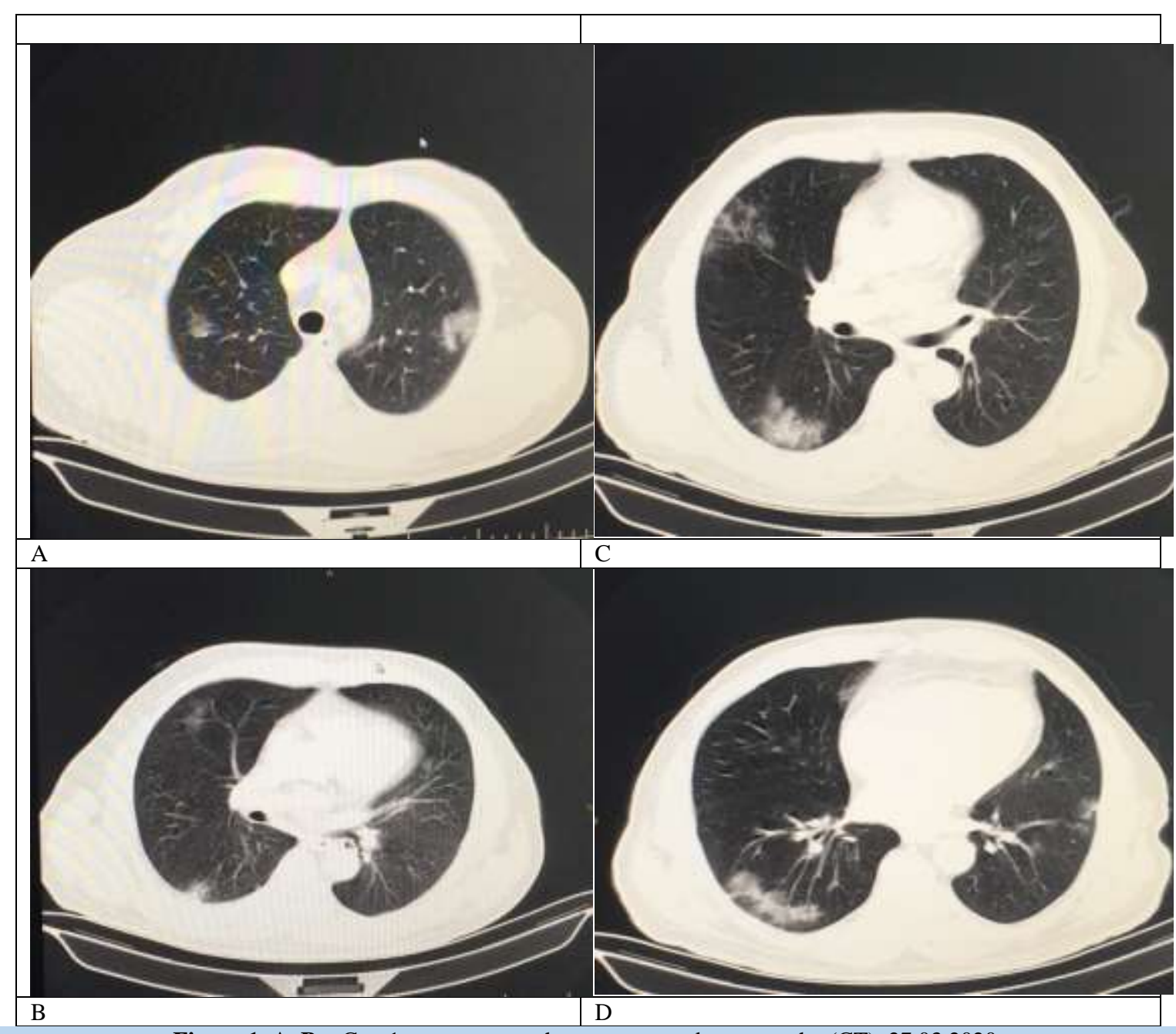

Figure 1. A, B - Case1, non-contrast thorax computed tomography (CT), 27.03.2020.

C, D - Case 1, control thorax CT, 06.04.2020.

The patient was hospitalized by isolation precautions. Levofloxacin 500 mg IV $1 \times 1$ and oseltamivir $75 \mathrm{mg}$ capsule $2 \times 1$ was started for treatment. Nasopharyngeal swab sample was taken for COVID-19 polymerase chain reaction (PCR) test on 27.03.2020 and 30.03.2020. However, PCR tests were negative. On 31.03.2020, hydroxychloroquine $200 \mathrm{mg}$ tablet was added to the treatment of the patient whose fever continuedon the first day as $2 \times 2$, then $2 \times 1$ and continued for five days. A nasopharyngeal swab sample was taken from the patient for the third time on 06.04.2020 for PCR testing and control CT without contrast was taken. The third PCR test was also negative. The control CT was reported as "draws attention in the form of patchy peripheral frosted glass in both lungs on the posterior segment of the right upper lobe on the right, and on the left at the level of the lower lobe of the upper lobe, on the right middle lobe, on the levels of the superior segment of both lower lobes and the posterobasal segment of both lower lobes. Thin linear density increases accompany the existing ground glass shapes and curvilinear streaks are added in basal segments. Occasionally, cobblestone views are formed. The findings are peripheral and bilateral. Compared to the older CT, there is an increase in the number and area of the lesion. The findings are compatible with the mid-term natural course in terms of its radiological course. Although progression is observed, it does not mean clinical progression. The patient's findings have been evaluated in favor of the natural process of COVID-19 infection and clinical evaluation is recommended for progression." Nasopharyngeal swab sample was taken from the patient for COVID-19 PCR test again on 08.04.2020. After the delivery of the rapid diagnostic kit, the patient was administered a rapid test with COVID-19 (SARS-CoV-2) Antibody Test Kit (Colloidal Gold) by recommendations of producer company (Anhui Deep Blue Medical Technology, Anhui, China). The last PCR test was negative but the rapid antibody test, COVID-19 immunoglobulin M (IgM) was positive (Figure 2). The patient, whose fever and cough complaints decreased in the follow-up and the respiratory distress did not develop, was discharged on the 15th day of hospitalization with the decision to follow up at home. 


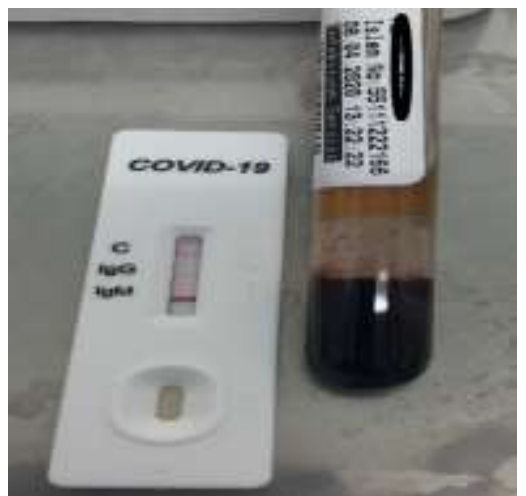

Figure 2. Case 1, rapid antibody test.

Case2: The second case was a 67-year-old female patient and was the first case's wife. The patient, who had a history of bus travel with the first case, was called to the Infectious Diseases Policlinic on 28.03.2020 after the first patient was hospitalized. Her complaint was soreness of all body, not cough and breathe distress. She had no fever. Her physical examination is normal. WBC: $4.71 \mathrm{~K} / \mu \mathrm{L}(4.6-10.2 \mathrm{~K} / \mu \mathrm{L})$, hemoglobin (HGB): $11.7 \mathrm{~g} / \mathrm{dl}(12.2-18.1 \mathrm{~g} / \mathrm{dl})$, hematocrit (HCT): 34.3\% (37.753.7\%), PLT: $148 \mathrm{~K} / \mu \mathrm{L}(142-424 \mathrm{~K} / \mu \mathrm{L}), \mathrm{CRP}: 11.2 \mathrm{mg} / \mathrm{L}(0-5 \mathrm{mg} / \mathrm{L})$ were resulted in laboratory tests. The non-contrast thoracic CT was reported as "The right lower lobe superior segment in both lungs, and both lower lobe anterobasal, laterobasal and posterobasal segments in the form of patches of peripherally located frosted glass, and patches of cobblestones are remarkable. The findings are highly suspicious for COVID-19 infection." (Figure 3). The patient was hospitalized for further examination, isolation and observation. The nasopharyngeal swab sample was taken for the COVID-19 PCR test on 28.03.2020. Levofloxacin $500 \mathrm{mg}$ IV $1 \times 1$ and oseltamivir $75 \mathrm{mg}$ capsule $2 \times 1$ were started for treatment. The PCR test was positive on 30.03.2020, then she was transferred to the city pandemic hospital.

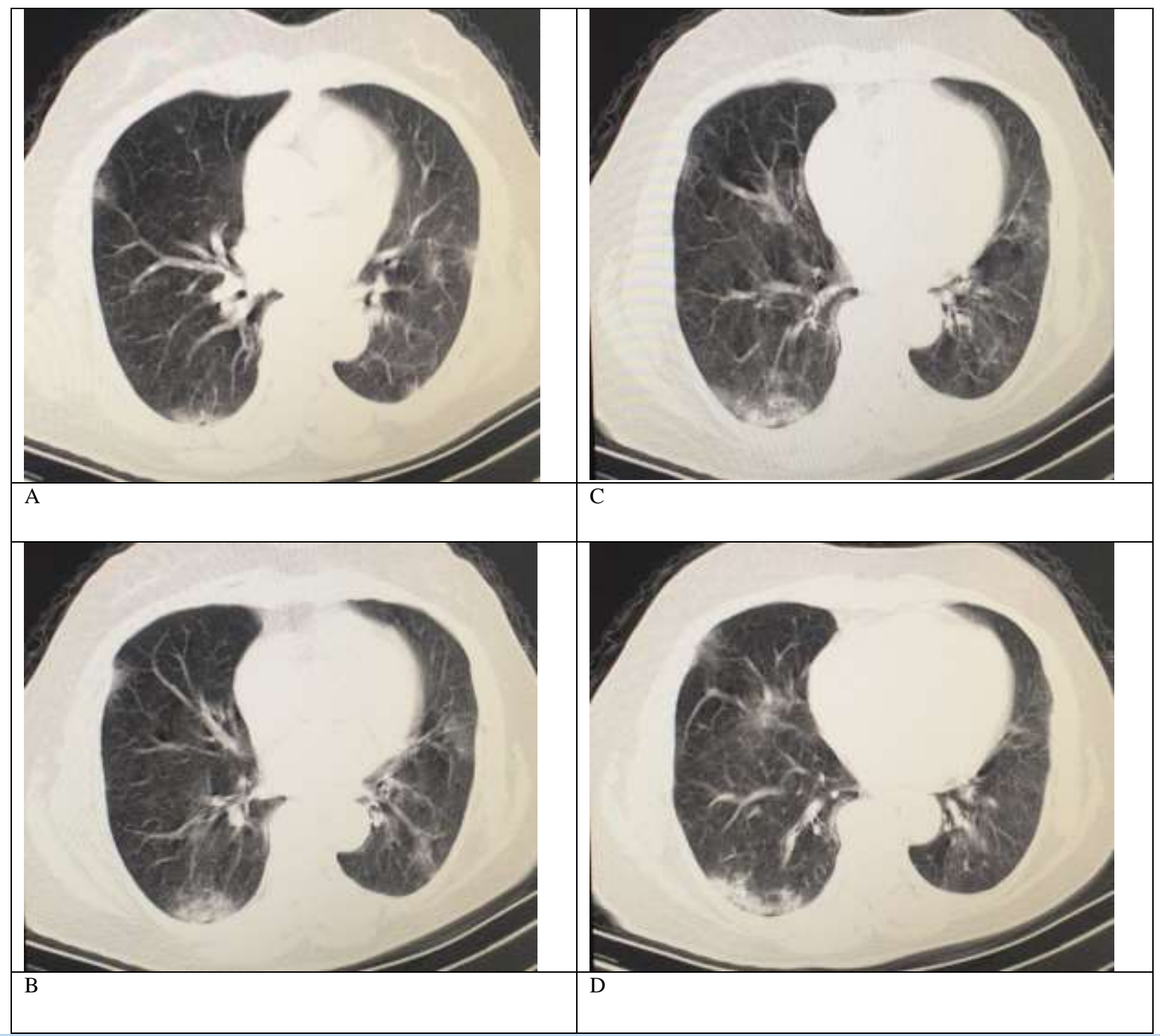

Figure 3. A, B, C, D. - Case 2, noncontrast thorax computed tomography, March 28, 2020.

\section{Discussion}

The first cases were detected in the United States, Russia, the Philippines, Singapore, Japan, Sweden, Canada, England, and Spain immediately after the World Health Organization declared a global public health emergency against coronavirus disease on January 30, 2020. This rapid spread demonstrated the importance of the need for fast and effective 
identification methods that can be used in health institutions dealing with the diagnosis and treatment of COVID-19. ${ }^{7}$

The gold standard for the diagnosis of COVID-19 is the identification of viral nucleic acid by polymerase chain reaction. However, the polymerase chain reaction method is a long time method that should be done meticulously. Also, some potential COVID-19 cases may have false negative results that may be detrimental to the control of the outbreak. ${ }^{8}$ We met a similar situation in the two cases we described above. The second case resulted in a positive COVID-19 PCR test, then she was recorded as definitive case, included the total number of cases in Turkey. However, despite the fact that the first case was clinically and radiologically compatible, positive COVID-19 rapid antibody test, the COVID-19 PCR test was negative and was not recorded as a definitive case.

In one retrospective study, the CT findings of 53 patients with COVID-19 were compared with PCR test. It has been reported that the diagnosis of viral pneumonia by CT could be three days earlier than PCR test, and CT could be standard method for COVID-19 diagnosis [7]. So, isolation and treatment of patients can be done earlier with rapid diagnosis and potential transmission can be prevented. Another fast, simple and sensitive method of diagnosing COVID-19 is to measure SARS-CoV-2 specific antibodies in peripheral blood. While the first defense mechanism against viral infections is immunoglobulin M (IgM), immunoglobulin G (IgG) is important in long-term immunity and immune memory [9]. In one study, it was reported that IgM antibodies could be measured in patient blood three to six days after SARS infection and eight days after IgG antibodies [10]. Hence, rapid detection of IgM and IgG antibodies will make an important contribution to the diagnosis and treatment of COVID-19. Li et al. reported the sensitivity as $88.66 \%$ and the specificity as $90.63 \%$ of rapid tests [8].These tests are important and quick method for local health institutions that do not have the possibility to perform PCR, because they do not require special equipment and personnel.

\section{Conclusion}

Although gold standard method for the definitive diagnosis of SARSCoV-2 infection is PCR, rapid antibody tests and CT findings are used in combination with PCR for a more effective struggle in the pandemic process would enhance rapid diagnosis of cases, necessary treatment and isolation measures to prevent transmission. It is thought that it would be useful to make case definitions.

\section{References}

1. World Health Organization. Summary of probable SARS cases with onset of illness from 1 November 2002 to 31 July 2003 (Based on data as of 31 December, 2003).

2. World Health Organization. Middle East respiratory syndrome coronavirus (MERS-CoV).

3. Gao Y, Li T, Han M, et al. (2020) Diagnostic utility of clinical laboratory data determinations for patients with the severe COVID-19. J Med Virol;92(7)791-6. PMID: 32181911.

4. Zhu N, Zhang D, Wang W, et al.(2020) A Novel Coronavirus from Patients with Pneumonia in China, 2019. N Engl J Med;382(8):727-33.PMID: 31978945.

5. World Health Organization. Coronavirus disease 2019 (COVID19) Situation report-23.

6. T.C. Sağlık Bakanlığı Halk Sağlığı Genel Müdürlüğü COVID19 (SARS-CoV-2 Enfeksiyonu) Rehberi 14 Nisan. 2020.

7. Li Y, Xia L.(2020) Coronavirus disease 2019 (COVID-19): Role of chest CT in diagnosis and management. AJR Am J Roentgenol;214(6):1280-76.PMID: 32130038.

8. Li Z, Yi Y, Luo X, et al.(2020) Development and clinical application of a rapid IgM-IgG combined antibody test for SARS-CoV-2 infection diagnosis. J Med Virol.Published online ahead of print. PMID: 32104917.

9. Racine R, Winslow GM.(2009) IgM in microbial infections: taken for granted?. Immunol Lett;125(2):79-85. PMID: 19539648.

10. Lee HK, Lee BH, Seok SH, et al.(2010) Production of specific antibodies against SARS-coronavirus nucleocapsid protein without cross reactivity with human coronaviruses $229 \mathrm{E}$ and OC43. J Vet Sci;11(2):165-7 . PMID: 20458159
This work is licensed under Creative Commons Attribution 4.0 License
Ready to submit your research? Choose Auctores and benefit from:

$$
\begin{aligned}
& \text { *ast, convenient online submission } \\
& \text { *igorous peer review by experienced research in your field } \\
& \text { * rapid publication on acceptance } \\
& \text { * unthors retain copyrights } \\
& \text { * immediate } \text { imol for all articles }
\end{aligned}
$$

At Auctores, research is always in progress.

Learn more www.auctoresonline.org/journals/clinical-medicalreviews-and-reports 